\title{
Secondary structures of short peptide chains in the gas phase: Double resonance spectroscopy of protected dipeptides
}

\author{
Wutharath Chin, Jean-Pierre Dognon, Clélia Canuel, François Piuzzi, \\ Iliana Dimicoli, and Michel Mons ${ }^{a}$ \\ Laboratoire Francis Perrin (URA CEA-CNRS 2453), Service des Photons, Atomes et Molécules, \\ Centre d'Etudes de Saclay, Bâtiment 522, 91191 Gif-sur-Yvette Cedex, France \\ Isabelle Compagnon \\ FOM Institute for Plasma Physics, Rijnhuizen, Edisonbaan 14, 3439 MN Nieuwegein, The Netherlands \\ Gert von Helden and Gerard Meijer \\ Fritz-Haber-Institut der Max-Planck-Gesellschaft, Faradayweg 4-6, 14195 Berlin, Germany
}

(Received 30 September 2004; accepted 4 November 2004; published online 21 January 2005)

\begin{abstract}
The conformational structure of short peptide chains in the gas phase is studied by laser spectroscopy of a series of protected dipeptides, Ac- $X x x-\mathrm{Phe}-\mathrm{NH}_{2}, X x x=\mathrm{Gly}$, Ala, and Val. The combination of laser desorption with supersonic expansion enables us to vaporize the peptide molecules and cool them internally; IR/UV double resonance spectroscopy in comparison to density functional theory calculations on Ac-Gly-Phe- $\mathrm{NH}_{2}$ permits us to identify and characterize the conformers populated in the supersonic expansion. Two main conformations, corresponding to secondary structures of proteins, are found to compete in the present experiments. One is composed of a doubly $\gamma$-fold corresponding to the $2{ }_{7}$ ribbon structure. Topologically, this motif is very close to a $\beta$-strand backbone conformation. The second conformation observed is the $\beta$-turn, responsible for the chain reversal in proteins. It is characterized by a relatively weak hydrogen bond linking remote $\mathrm{NH}$ and $\mathrm{CO}$ groups of the molecule and leading to a ten-membered ring. The present gas phase experiment illustrates the intrinsic folding properties of the peptide chain and the robustness of the $\beta$-turn structure, even in the absence of a solvent. The $\beta$-turn population is found to vary significantly with the residues within the sequence; the Ac-Val-Phe- $\mathrm{NH}_{2}$ peptide, with its two bulky side chains, exhibits the largest $\beta$-turn population. This suggests that the intrinsic stabilities of the $2{ }_{7}$ ribbon and the $\beta$-turn are very similar and that weakly polar interactions occurring between side chains can be a decisive factor capable of controlling the secondary structure. (C) 2005 American Institute of Physics. [DOI: 10.1063/1.1839862]
\end{abstract}

\section{INTRODUCTION}

Due to the tremendous progress in computational possibilities, reliable quantum mechanical calculations as ab initio or density functional theory (DFT) can nowadays be performed on molecular objects having several tens of heavy atoms. Over the last years, numerous groups have thus studied unsolvated model peptide chains of increasing size using various levels of theory. ${ }^{1-15}$ In a few cases, structures of small peptides protected on both their $\mathrm{C}$ and $\mathrm{N}$ termini, have been studied in order to investigate the competition between different protein secondary structures, such as $\beta$-turns, $\beta$-strands, and $\alpha$ or $3_{10}$ helices. ${ }^{1,3,6,12-15}$

Computational studies could not be easily compared to experimental investigations, which have been carried out so far in condensed phases. A large amount of data on small protected peptides has thus been obtained using IR and circular dichroism spectroscopy, and more seldom using NMR or x-ray diffraction. ${ }^{16-19}$ The type of intramolecular H-bonding expected in peptides was already well es-

\footnotetext{
a) Author to whom correspondence should be addressed. Electronic mail: mmons@cea.fr
}

tablished in the original works of Ramachandran and Venkatachalam. ${ }^{16}$ However, the understanding of the measurements is often hampered by spectral congestion resulting from the coexistence of multiple conformers and by spectral shifts due to solvent effects in liquid phase or intermolecular interactions in crystals. ${ }^{19}$

Modern methods for preparing molecules in the gas phase such as laser desorption followed by fast cooling in a supersonic expansion, ${ }^{20,21}$ allow the use of sophisticated UV and IR/UV double resonance laser spectroscopic techniques. $^{22,23}$ In general the better resolution and the conformer-selective experiments achieved in gas phase spectroscopic techniques provide more precise information than condensed phase studies. Such conformer-selective data can be directly compared to results from computations and allow a straightforward assessment of the theoretical methods. After the pioneering work of Levy and co-workers on the amino acid tryptophan and its derivatives, ${ }^{20}$ several experimental groups focused their efforts on other amino acids and peptides molecules, either having the $\mathrm{N}$ - and $\mathrm{C}$-termini unmodified $^{24-30}$ or chemically protected..$^{31-36}$ In particular, $\mathrm{N}$-acetylated and $\mathrm{C}$-amidated termini (chart 1) allow to study 
the intrinsic folding properties of the peptide backbone as they introduce peptide bonds in the system.

For instance, the study of protected amino-acids permits to address the issue of local preferences. A $\gamma$-fold with the formation of a $\mathrm{H}$-bond in a seven-atom ring (named $C_{7}$, see Chart 1) has been found experimentally for protected alanine (Ala) ${ }^{37}$ tryptophan (Trp), ${ }^{31,32}$ and phenylalanine (Phe) ${ }^{34-36}$ and has been confirmed by high level $a b$ initio calculations. ${ }^{2,4,6,8,10,38-40}$ In the case of the aromatic residues Trp and Phe, extended $\beta$-strandlike structures (referred to as $\beta_{\mathrm{L}}$ ) energetically compete with $\gamma$-folds and are also observed experimentally. ${ }^{31,32,35,36}$ Their stability results from the existence of a weak $C_{5}$ interaction between neighboring $\mathrm{NH}$ and $\mathrm{CO}$ moieties, resulting in an extended backbone, which also allows the formation of a stabilizing $\mathrm{NH} \cdots \pi$ interaction between the aromatic ring and the trans $\mathrm{NH}$ of the C-terminal amide group. ${ }^{35,41}$

Chart 1. Possible intramolecular $>\mathrm{NH} \cdots \mathrm{O}=\mathrm{C}\langle$ interactions in the protected dipeptides studied.

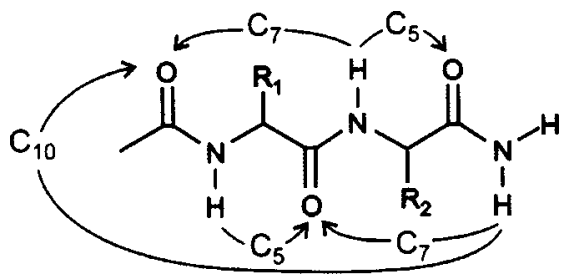

Longer protected peptides, which are able to form secondary structures, have only been recently studied experimentally in the gas phase. ${ }^{35}$ Even in a protected peptide containing only two residues, several secondary structures can be expected, either based upon a succession of local conformational preferences (such as the 27 ribbons, which correspond to a daisy chain of $C_{7} \gamma$-folds, or like the $\beta$-strands corresponding to a fully extended backbone, stabilized by a weak $C_{5}$ interaction), or based upon the formation of $\mathrm{H}$-bonds between more remote $\mathrm{NH}$ and $\mathrm{CO}$ sites along the backbone (such as the $\beta$-turns, stabilized by $C_{10}$ bonds). For the protected dipeptides Ac-Phe-Pro- $\mathrm{NH}_{2}$ and Ac-Pro-Phe- $\mathrm{NH}_{2}$, we recently reported the observation of a double $\gamma$-fold as well as a specific type of $\beta$-turn with the Pro amide bond in a cis conformation. ${ }^{35}$

The present paper provides evidence for the spontaneous formation of secondary structures in the gas phase, namely, $\beta$-turns and 27 ribbons, and demonstrates a sequencedependent competition between these forms. As model systems, we choose a series of protected dipeptides: Ac- $X x x$-Phe- $\mathrm{NH}_{2}, X x x=$ Gly (glycine), Ala, and Val (valine). One of the residues is a phenylalanine, which is the UV chromophore needed in our IR/UV experiments; the other is an aliphatic residue, Gly, Ala, or Val. Resonant two-photon ionization (R2PI) is used to distinguish the UV spectral signatures of each conformer. IR/UV double resonance technique is used to record the conformer-selective IR spectra in both near- $(3 \mu \mathrm{m})$ and mid- $(5-8 \mu \mathrm{m})$ IR range, enabling us to characterize the H-bonding network by interrogating the $\mathrm{NH}$ and $\mathrm{CO}$ stretch vibrations of each conformer. A preliminary structural assignment resulting from a qualitative analysis of the IR data is proposed and confirmed by comparison to calculated IR vibrational spectra.

\section{METHODS}

\section{A. Experimental methods}

The IR/UV double resonance spectra were recorded on different set-ups depending on the IR spectral range considered. The amide A region (NH stretches, $3 \mu \mathrm{m}$ ) was recorded in Saclay, on a setup described previously. ${ }^{35}$ The second harmonic of a Nd:YAG (YAG-yttrium aluminum garnet) laser (1-5 mJ) is used to desorb peptide molecules (Epyitop Co., Nîmes) from the surface of a pellet, obtained by pressing a mixture of graphite and peptide powders. The pellet surface is located $1.5 \mathrm{~mm}$ below the nozzle of a pulsed valve (general valve) and is translated during the experiment in order to allow the laser to hit fresh spots. The desorption plume is crossed at right angle by the pulsed molecular jet (nozzle diameter $0.3 \mathrm{~mm} ; 4$ bars of argon pressure) which picks up and cools the peptide molecules and then entrains them through a skimmer into the interaction region of a time-offlight (TOF) mass spectrometer. The UV light of a first laser (frequency-doubled Lambda Physik FL 3000, pumped by an EMG 103 Lambda Physik excimer laser) is used to excite the first singlet electronic state of the molecules. The UV absorption is obtained by recording the mass-selected R2PI signal collected in the TOF spectrometer as a function of the UV excitation frequency. The IR absorption is measured using the IR/UV double resonance technique. ${ }^{22,23}$ The IR light is the idler output of an optical parametric oscillator (OPO), working with $\mathrm{LiNbO}_{3}$ crystal, pumped by the fundamental light of a Nd:YAG laser. The OPO beam, used as a "pump" laser, crosses the molecular beam and excites molecules when its frequency matches an IR absorption band. The OPO bandwidth $\left(1 \mathrm{~cm}^{-1}\right)$ is achieved by an intracavity PérotFabry etalon and pulse energies are on the order of 1-4 mJ. The conformer-selective IR absorption spectra are obtained by monitoring ion dips on the R2PI signal of the UV "probe" laser as a function of the IR wavelength. Due to a strong absorption in the OPO crystal, no spectra could be recorded in the 2.85-2.89 $\mu \mathrm{m}$ region, which corresponds to the range of the stretch frequency of free NH moieties.

The IR absorption in the amide I (CO stretches 5.7-6.1 $\mu \mathrm{m})$ and amide II (NH bends $6-8 \mu \mathrm{m}$ ) regions was recorded at the free-electron laser facility FELIX in Nieuwegein, using a set-up described previously. ${ }^{28}$ Conceptually the setup is similar to that in Saclay, however, it differs in some practical details. The peptide powder is spread onto a translatable graphite surface and the fundamental radiation of a Nd:YAG laser is used as desorption laser. The most important difference stems from the nature of the mid-IR radiation source: the free-electron laser FELIX. Its output consists of microsecond-long bursts (macropulses) of light at a repetition rate of $5 \mathrm{~Hz}$, containing micropulses of picoseconds duration at a $1 \mathrm{GHz}$ repetition rate. The FELIX parameters are optimized for an intense output in the 5-8 $\mu \mathrm{m}$ region (typically $50 \mathrm{~mJ}$ per macropulse); the line width is typically $1 \%$ full width at half maximum, i.e., $\sim 15 \mathrm{~cm}^{-1}$ in the region scanned. The unfocussed IR beam crosses the molecular beam and is aligned counterpropagating to the slightly focused UV photoionization beam from a Nd:YAG pumped 


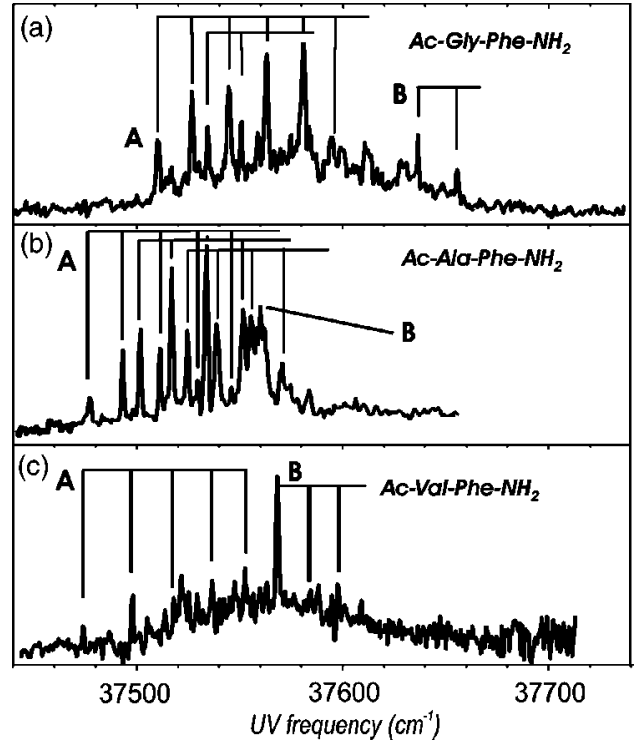

FIG. 1. UV spectra of Ac- $X x x$-Phe- $\mathrm{NH}_{2}, X x x=$ Gly (a), Ala (b), and Val (c) in the origin region of the first electronic transition $\left(\pi \pi^{*}\right)$ of Phe, obtained by mass-selected resonant two-photon ionization spectroscopy. IR/UV double resonance experiments demonstrate that only two main conformers, labeled $A$ and $B$, are responsible for the spectra observed. The origin transition and progressions are indicated.

dye laser (Spectra Physics GCR-100/PDL3), operating at $10 \mathrm{~Hz}$.

The UV signals recorded under "IR on" and "IR off" conditions are separately averaged over typically 100 shots and normalized to the IR off signal in order to minimize the signal fluctuations. At FELIX, the spectra obtained are then corrected for the intensity variations of IR light over the amide I and II scanning range.

\section{B. Theoretical methods}

Experimental IR data are compared to IR calculated spectra of a set of selected conformations of the simplest peptide (Ac-Gly-Phe- $\mathrm{NH}_{2}$ ) using DFT methods. These conformations were chosen either to represent the classic secondary structures ( 27 ribbon, $\beta$-strand, and $\beta$-turn), or to account qualitatively for the specific IR features observed. In both cases, the orientation of the side-chain Phe was chosen in order to account also for the weak NH- $\pi$ interactions observed experimentally. The optimized geometry of these conformations and their harmonic vibrational frequencies were obtained at the B3LYP/6-31+ $\mathrm{G}(d)$ level using the GAUSSIAN 98 program. ${ }^{42}$ The relative energies of the conformations were estimated at the MP2/6-31+ G(d)//B3LYP/6-31 $+\mathrm{G}(d)$ level, in order to account for the important effects of dynamical electron correlation in peptides, $, 2,4,6,8,10,38,39$ and corrected for the zero-point vibrational energy estimated at the B3LYP/6-31+ $\mathrm{G}(d)$ level of theory.

\section{RESULTS}

\section{A. UV spectroscopy}

Near UV spectra of the jet-cooled dipeptides in the absorption region of the Phe chromophore were obtained by mass-resolved R2PI spectroscopy and are shown in Fig. 1.

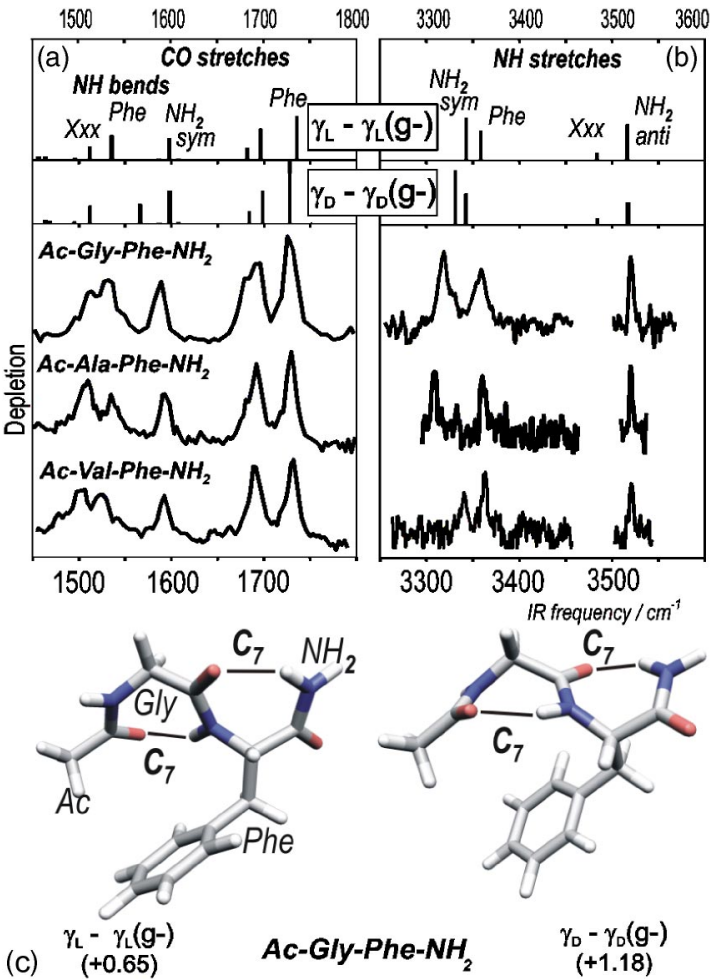

FIG. 2. IR spectra of the main conformers $A$ of Ac- $X x x$-Phe- $\mathrm{NH}_{2}, X x x$ $=$ Gly, Ala, and Val: (a) in the $\mathrm{CO}$ stretch and $\mathrm{NH}$ bend regions (amide $\mathrm{I}$ and II) and (b) in the NH stretch region (amide $A$ ), as obtained in IR/UV double resonance experiments. The spectra are obtained by tuning the UV laser to the most intense conformer $A$ band in the respective UV spectra. For comparison, DFT calculated stick spectra for two stable conformations [shown in (c)] of Ac-Gly-Phe- $\mathrm{NH}_{2}$ matching the two experimental H-bonds $\left(C_{7}-C_{7}\right)$ are also given (top panels). The harmonic frequencies have been scaled by a factor of $0.98,0.97$, and 0.96 to account for anharmonicity in the amide I, II, and $A$ regions, respectively (Refs. 35 and 41). The weak coupling between the several NH stretch oscillators allows to describe them as local modes. In the amide I and II regions, the modes are much more coupled and labels indicate the major mode component. Spectra could not be recorded in the $3470-3500 \mathrm{~cm}^{-1}$ region because of an absorption in the IR OPO crystal. The MP2/6-31+ G(d)//B3LYP/6-31+ G(d) ZPE-corrected energy ( $\mathrm{kcal} / \mathrm{mol}$; between brackets) of each conformation is given relative to the most stable form found theoretically: the $\beta$-turn type I $(g+)$, shown in Fig. 3(c).

The three spectra show progressions of bands superimposed with additional isolated bands or short progressions. The relative intensities of these features are found to vary along the series. IR/UV double resonance experiments carried out on the main progressions labeled $A$ and $B$ show that they result from different conformers that do not interconvert in the jet. Conformer $A$ is responsible for the richest progression and turns out to be the prevalent form for $X x x=$ Gly and Ala. Conformer $B$, responsible for short progressions or isolated bands, is much more intense with residue Val. For the Ala containing peptide, the bands of conformer $B$ are embedded in a complex band pattern resulting from $A$.

\section{B. IR spectroscopy}

Intense and resolved UV resonances of $A$ and $B$ have been selected to record the IR spectra of the corresponding conformers using the IR/UV double resonance technique (Figs. 2, 3; Tables I and II). For the three molecules investi- 


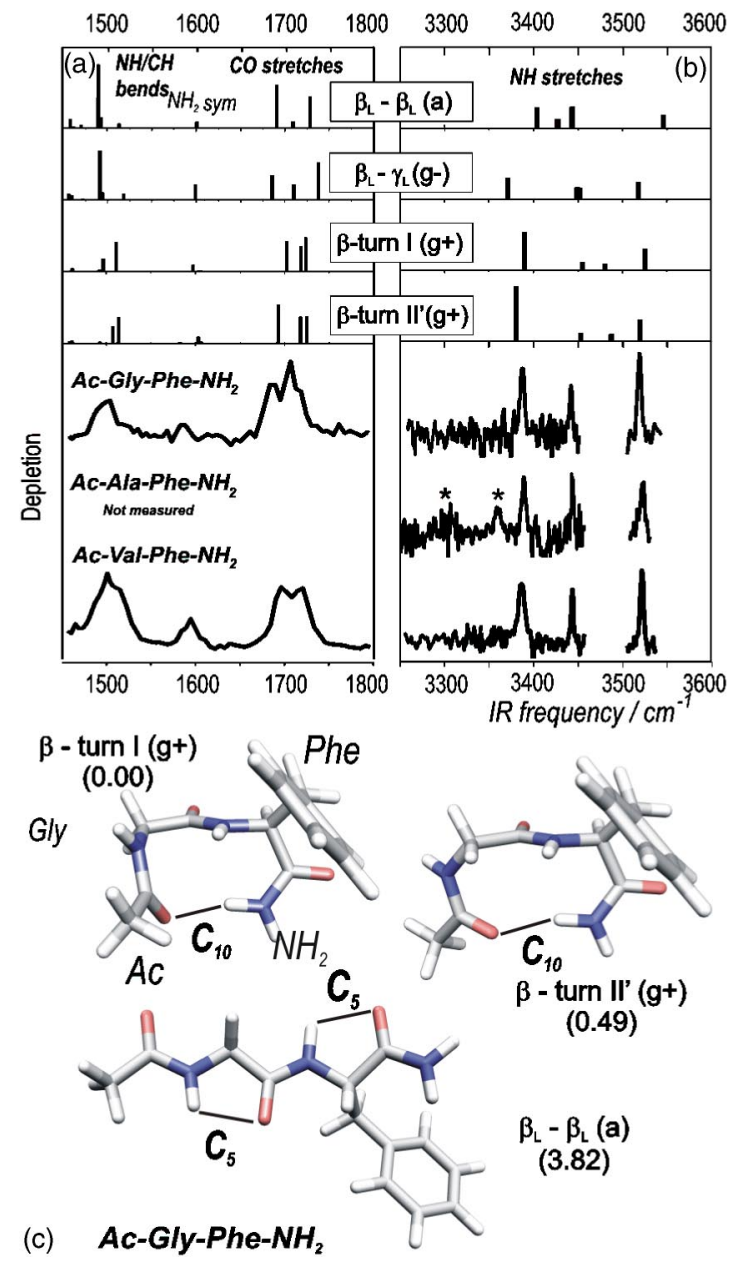

FIG. 3. IR spectra of conformers $B$ of Ac- $X x x$-Phe- $\mathrm{NH}_{2}, X x x=$ Gly, Ala, and Val: (a) in the $\mathrm{CO}$ stretch and $\mathrm{NH}$ amide bend regions (amide I and II) and (b) in the $\mathrm{NH}$ stretch region (amide $A$ ). Weak features marked with an asterisk correspond to IR bands of conformer $A$ that are also visible in the spectrum due to a partial spectral overlap of UV bands of $A$ and $B$ (see Fig. 1). The top panels show the DFT calculated stick spectra of four selected stable conformations of Ac-Gly-Phe- $\mathrm{NH}_{2}$ (see text), the three most stable of those are shown in (c). Their MP2/6-31+ G(d)//B3LYP/6-31+ G(d) ZPEcorrected energy ( $\mathrm{kcal} / \mathrm{mol}$; between brackets) is given relative to the most stable form: $\beta$-turn type I $(g+)$.

gated, the UV bands of the same type of conformer $(A$ or $B$ ) exhibit strikingly similar spectral IR signatures.

Conformers $A$. The amide $A$ region [NH stretches, Fig. 2(b), Table I] of all the dipeptides investigated shows three bands. Each band should be assigned to one of the four NH stretch chromophores in the molecule. Free or weakly perturbed $\mathrm{NH}$ groups (for instance, engaged in a $\pi \mathrm{H}$-bond or a $C_{5}$ interaction) are usually located in the $3420-3550 \mathrm{~cm}^{-1}$ range. ${ }^{35,43,44}$ The two bands found to the red from this region unambiguously indicate the presence of two strong intramolecular H-bonds. A third band is found around $3520 \mathrm{~cm}^{-1}$ and corresponds to a free NH stretch. The fourth band expected is yet missing and is presumably located in the region of free NH stretches, not covered by the OPO crystal $\left(3470-3500 \mathrm{~cm}^{-1}\right)$.

Interestingly, the $\mathrm{NH}_{2}$ group of the C-terminal amide provides us with a very useful piece of information. In the case of a free $\mathrm{NH}_{2}$ group, the vibrational coupling between the two NH stretch oscillators leads to a doublet whose symmetric and antisymmetric components are split by $117 \mathrm{~cm}^{-1} \cdot 35,43,44$ When one of these oscillators is perturbed, for instance by a H-bond, the low frequency component, which corresponds to the symmetric mode, is red-shifted due to the effects of H-bonding. The high frequency or antisymmetric mode, although unperturbed by the H-bond is however slightly red-shifted due to the residual vibrational coupling between both oscillators. ${ }^{35,43}$ In the limit of very strong $\mathrm{H}$-bonding, the vibrational coupling becomes negligible and the antisymmetric mode converges towards the value it would exhibit in the absence of vibrational coupling, namely, that of a free $\mathrm{NH}$ oscillator at the midvalue of the free doublet around $3490 \mathrm{~cm}^{-1} .{ }^{35}$ In other words, any small red-shift of the high frequency component of the $\mathrm{NH}_{2}$ group indicates the involvement of one of its $\mathrm{NH}$ oscillators in a H-bond. In the IR spectra, the blue most peak is located at $3520 \mathrm{~cm}^{-1}$, this is significantly lower than the unperturbed value $\left[\sim 3550 \mathrm{~cm}^{-1}\right.$ (Refs. 35 and 44)] and is an indication of the involvement of the $\mathrm{NH}_{2}$ group in a H-bond.

The H-bonding picture emerging from IR amide $A$ spectroscopy is supported by amide I data [Fig. 2(a), Table I], which exhibits a doublet pattern. The blue most band does correspond to a free or nearly free $\mathrm{CO}$ stretch mode, expected to lie between $1700 \mathrm{~cm}^{-1}$ and $1730 \mathrm{~cm}^{-1}$. The redshifted peak near $1690 \mathrm{~cm}^{-1}$, corresponds to a bound CO region. In addition, this peak exhibits a shoulder on its red side, at least for $X x x=$ Gly and Ala. These observations corroborate the presence of one free $\mathrm{CO}$ group and two H-bonded ones.

The spectra in the NH bend region [amide II, Fig. 2(a)] are dominated by three broad and intense bands spread over $100 \mathrm{~cm}^{-1}$. Because the $\mathrm{NH}$ bend modes are strongly coupled, spectral assignment is less obvious.

Conformers $B$. The three IR spectra (Fig. 3, Table II) differ qualitatively from those of conformers $A$. The amide $A$ region [NH stretch, Fig. 3(b)] of conformers $B$ shows three bands. Only one band is observed below $3400 \mathrm{~cm}^{-1}$, indicative of a unique moderately strong $\mathrm{H}$-bond in the molecule.

This $\mathrm{NH}$ group shows a weaker $\mathrm{H}$-bond than in conformer $A$, even weaker than in the $\gamma$-folded structures of Ac-Phe- $\mathrm{NH}_{2} \cdot{ }^{35,41}$ Again the location of the blue most band in the $3520 \mathrm{~cm}^{-1}$ region indicates a $\mathrm{H}$-bonded C-terminal amino group. The red most band is therefore due to one of the $\mathrm{NH}$ moieties of the $\mathrm{NH}_{2}$ group, the other being free. A third band near $3450 \mathrm{~cm}^{-1}$ corresponds to a weakly interacting $\mathrm{NH}$ group (either $C_{5}$ or $\mathrm{NH}-\pi$ interaction) and, as in the case of conformer $A$, a fourth band is missing in the spectra. The amide I and II data [Fig. 3(a)] reveal different patterns compared to conformer $A$ [Fig. 2(a)], namely, a broad, barely resolved amide I feature in the $1690-1720 \mathrm{~cm}^{-1}$ range, suggesting a much weaker H-bonding network.

\section{DISCUSSION}

The analysis of the IR data presented above suggests that (i) conformers having similar UV signatures exhibit the same conformation, (ii) in conformer $A$, two H-bonds are present 
TABLE I. Spectroscopic UV origin band and IR vibrational frequencies $\left(\mathrm{cm}^{-1}\right)$ of conformers $A$ of Ac-Gly- $\mathrm{Phe}^{-\mathrm{NH}_{2}}$, Ac-Ala-Phe- $\mathrm{NH} \mathrm{H}_{2}$, and Ac-Val-Phe- $\mathrm{NH}_{2}$ compared to calculated frequencies $\left(\mathrm{cm}^{-1}\right)$ of $\gamma-\gamma \mathrm{B} 3 \mathrm{LYP} / 6-31+\mathrm{G}(d)$ optimized structures of Ac-Gly-Phe-NH $\mathrm{N}_{2}$ in the amide I/II and amide $A$ regions (scaling factors of $0.98,0.97$, and 0.96 , respectively). Intensities $(\mathrm{km} / \mathrm{mol})$ are given in brackets.

\begin{tabular}{|c|c|c|c|c|c|c|c|c|}
\hline $\begin{array}{c}\text { Species } \\
\text { conf. } A \\
\text { UV frequency }\end{array}$ & $\begin{array}{c}\text { Ac-Gly-Phe- } \mathrm{NH}_{2} \\
\text { expt. } \\
37510\end{array}$ & $\begin{array}{c}\text { Ac-Ala-Phe- } \mathrm{NH}_{2} \\
\text { expt. } \\
37477\end{array}$ & $\begin{array}{c}\text { Ac-Val-Phe- } \mathrm{NH}_{2} \\
\text { expt. } \\
37474\end{array}$ & \multicolumn{5}{|c|}{$\begin{array}{c}\text { Ac-Gly-Phe- } \mathrm{NH}_{2} \\
\text { calculated IR frequencies }\end{array}$} \\
\hline & \multicolumn{3}{|c|}{ Experimental IR frequencies } & \multicolumn{2}{|c|}{$\gamma_{\mathrm{L}}-\gamma_{\mathrm{L}}(g-)$} & \multicolumn{2}{|c|}{$\gamma_{D^{-}} \gamma_{D}(g-)$} & Assignment \\
\hline \multirow{3}{*}{$\begin{array}{l}\text { Amide II } \\
\text { region } \\
(\mathrm{NH} \\
\text { bend) }\end{array}$} & 1510 & 1508 & 1502 & $\begin{array}{l}1510 \\
(128)\end{array}$ & Free & $\begin{array}{l}1510 \\
(131)\end{array}$ & Free & NH Gly bend \\
\hline & 1531 & 1534 & 1525 & $\begin{array}{l}1535 \\
(240)\end{array}$ & $C_{7}$ & $\begin{array}{l}1565 \\
(146)\end{array}$ & $C_{7}$ & NH Phe bend \\
\hline & 1588 & 1592 & 1593 & $\begin{array}{l}1597 \\
(209)\end{array}$ & $C_{7}$ & $\begin{array}{l}1597 \\
(251)\end{array}$ & $C_{7}$ & $\begin{array}{l}\mathrm{NH}_{2} \text { sym } \\
\text { bend }\end{array}$ \\
\hline \multirow{3}{*}{$\begin{array}{l}\text { Amide I } \\
\text { region } \\
\text { (CO } \\
\text { stretch) }\end{array}$} & $1678^{\mathrm{a}}$ & $1680^{\mathrm{a}}$ & Not resolved & $\begin{array}{l}1681 \\
(114)\end{array}$ & $C_{7}$ & $\begin{array}{c}1683 \\
(91)\end{array}$ & $C_{7}$ & $\begin{array}{l}\text { Mostly CO } \\
\text { Gly stretch }\end{array}$ \\
\hline & 1695 & 1691 & 1689 & $\begin{array}{l}1695 \\
(307)\end{array}$ & $C_{7}$ & $\begin{array}{l}1697 \\
(250)\end{array}$ & $C_{7}$ & $\begin{array}{l}\text { Mostly CO Ac } \\
\text { stretch }^{\mathrm{b}}\end{array}$ \\
\hline & 1725 & 1729 & 1733 & $\begin{array}{l}1735 \\
(435)\end{array}$ & Free & $\begin{array}{l}1726 \\
(481)\end{array}$ & Free & $\begin{array}{l}\text { CO Phe } \\
\text { stretch }\end{array}$ \\
\hline \multirow{4}{*}{$\begin{array}{l}\text { Amide } A \\
\text { region } \\
(\mathrm{NH} \\
\text { stretch) }\end{array}$} & 3319 & 3308 & 3340 & $\begin{array}{l}3342 \\
(157)\end{array}$ & $C_{7}$ & $\begin{array}{l}3331 \\
(236)\end{array}$ & $C_{7}$ & $\begin{array}{l}\text { NH Phe } \\
\text { stretch }\end{array}$ \\
\hline & 3359 & 3360 & 3362 & $\begin{array}{l}3358 \\
(102)\end{array}$ & $C_{7}$ & $\begin{array}{l}3342 \\
(127)\end{array}$ & $C_{7}$ & $\begin{array}{l}\mathrm{NH}_{2} \text { sym } \\
\text { stretch }\end{array}$ \\
\hline & $\mathrm{c}$ & $\mathrm{c}$ & $\mathrm{c}$ & $\begin{array}{l}3484 \\
(109)\end{array}$ & Free & $\begin{array}{c}3484 \\
(26)\end{array}$ & Free & $\begin{array}{l}\text { NH Gly } \\
\text { stretch }\end{array}$ \\
\hline & 3520 & 3520 & 3520 & $\begin{array}{c}3516 \\
(77)\end{array}$ & Free & $\begin{array}{c}3517 \\
(94)\end{array}$ & Free & $\begin{array}{l}\mathrm{NH}_{2} \text { anti } \\
\text { stretch }\end{array}$ \\
\hline
\end{tabular}

${ }^{\text {a Shoulder. }}$

${ }^{\mathrm{b}}$ The CO stretching modes of residue Gly and the acetyl group are strongly coupled to each other.

${ }^{\mathrm{c}}$ The missing NH stretching band is located in the absorption region of the OPO crystal.

while only one is present in conformer $B$, and (iii) in both types of conformers, the terminal $\mathrm{NH}_{2}$ group acts as a proton donor.

From the observed spectra and the possible H-bond pattern in such systems (Chart 1), a qualitative assignment can already be proposed for conformer $A$. A double $\gamma$-folded structure, with two entangled $C_{7}$ bonds corresponding to the $2{ }_{7}$ ribbon, would be consistent with the experiment. Such a structure also fulfills the local backbone conformational preference on both Phe and $X x x$ residues.

The case of conformers $B$ is less clear as two possible structures can account for the IR data. In particular the two $\mathrm{NH}$ stretch bands in the red part of the spectrum indicate, either a $C_{7} \mathrm{H}$-bond on Phe residue with a $C_{5}$ interaction on $X x x$ (without any significant $\mathrm{NH}$ interaction), or a folded $\beta$-turn structure with a $C_{10} \mathrm{H}$-bond accompanied by a weak $\mathrm{NH}-\pi$ interaction. For several reasons, the former structure is less probable: on the one hand, such a $C_{5}-C_{7}$ structure does not correspond to a succession of local conformational preferences along the backbone, neither on residue $X x x\left(C_{5}\right.$ instead of $\left.C_{7}\right)$, nor on Phe $\left(C_{7}\right.$ instead of $\left.C_{5}\right)$. On the other hand, this $C_{5}-C_{7}$ conformation is probably destabilized compared to the topologically similar $C_{7}-C_{7}$ structure, and the presumably low barrier between these similar conformations would be easily crossed during the expansion. It should be noted that the $\beta$-turn does neither correspond to a succession of local preferences. However, it is stabilized by a medium strength $C_{10}$ H-bond and is different enough in topology from the $C_{7}-C_{7}$ conformation to not undergo to this double $\gamma$-folded form during the cooling process. Another reason deals with the strength of the bond observed: both the amide $A$ and I regions indicate a rather weak interaction that does not fit to what is expected for a typical $C_{7} \mathrm{H}$-bond on Phe. ${ }^{35,41}$ Owing to these considerations we tentatively assign conformers $B$ to a $\beta$-turn structure based on a $C_{10} \mathrm{H}$-bond.

Such assignments should be strengthened by a comparison to quantum chemistry calculations. Several strategies can be used: First, one could explore the potential energy landscape of the systems, and try to find the most stable structures by comparing all local minima to each other. However, in flexible systems such as peptides this is a cumbersome task, even for protected dipeptides. ${ }^{35,45}$ The other option, chosen in the present work, consists of restricting the set of conformations on which high-level calculations are performed by using educated guesses for the structures. Selection criteria are either secondary structures or local conformational preferences of the backbone, that fulfill the H-bond schemes deduced from the qualitative analysis developed above.

In the present case, calculations have been carried out on the simplest system of the series Ac-Gly-Phe- $\mathrm{NH}_{2}$. The following backbone conformations were investigated: $C_{7}-C_{7}$ (2 7 ribbon), $C_{5}-C_{5}$ ( $\beta$-strand), $C_{10}\left(\beta\right.$-turn), and $C_{5}-C_{7}$. Such specifications do not uniquely define the system. A large number of conformations, only differing from subtle changes in the backbone and the Phe side-chain orientation, 
TABLE II. Spectroscopic UV origin band and IR vibrational frequencies $\left(\mathrm{cm}^{-1}\right)$ of conformers $B$ of Ac-Gly-Phe- $-\mathrm{NH}_{2}, \mathrm{Ac}-\mathrm{Ala}-\mathrm{Phe}-\mathrm{NH} \mathrm{H}_{2}$, and Ac-Val-Phe- $\mathrm{NH}_{2}$ compared with calculated frequencies $\left(\mathrm{cm}^{-1}\right)$ of $\beta$-turns type $\mathrm{I}(g+)$, type $\mathrm{II}^{\prime}(g+), \beta_{\mathrm{L}^{-}} \gamma_{\mathrm{L}}(g-)$, and $\beta_{\mathrm{L}}-\beta_{\mathrm{L}}(a) \mathrm{B} 3 \mathrm{LYP} / 6-31+\mathrm{G}(d)$ optimized structures of Ac-Gly-Phe- $\mathrm{NH}_{2}$ in the amide I/II and amide $A$ regions (scaling factors of $0.98,0.97$, and 0.96 , respectively). Intensities (km/mol) are given in brackets. The calculated data in agreement with the experimental data are indicated in italics.

\begin{tabular}{|c|c|c|c|c|c|c|c|c|c|c|c|c|c|c|}
\hline \multirow{6}{*}{$\begin{array}{l}\text { Species } \\
\text { conf. } B\end{array}$} & \multicolumn{3}{|c|}{ Ac- $X x x$-Phe- $\mathrm{NH}_{2}$ exp } & & & & & & & & & & & \\
\hline & $\begin{array}{l}X x x=\text { Gly } \\
\text { Experime }\end{array}$ & Ala & Val & & & & & & & & & & & \\
\hline & \multicolumn{3}{|c|}{ Experimental UV frequencies } & & & & & & & & & & & \\
\hline & 37636 & 37560 & 37569 & \multicolumn{11}{|c|}{ Ac-Gly-Phe- $\mathrm{NH}_{2}$} \\
\hline & \multicolumn{3}{|c|}{ Experimental IR frequencies } & \multicolumn{11}{|c|}{ Calculated IR frequencies } \\
\hline & & & & $\begin{array}{r}\text { Typ } \\
\beta \text {-turn }\end{array}$ & $\begin{array}{l}\text { e I } \\
(g+)\end{array}$ & $\begin{array}{r}\text { Type } \\
\beta \text {-turn }\end{array}$ & $\begin{array}{l}\mathrm{II}^{\prime} \\
(g+)\end{array}$ & Assignment & $\beta_{\mathrm{L}^{-}}-\gamma_{\mathrm{L}}(g$ & & Assignment & $\beta_{\mathrm{L}^{-}}-\beta$ & $\mathrm{L}(a)$ & Assignment \\
\hline \multirow[t]{3}{*}{$\begin{array}{l}\text { Amide II } \\
\text { region } \\
\text { (NH } \\
\text { bend) }\end{array}$} & 1504 & & 1501 & $\begin{array}{l}1497 \\
(145)\end{array}$ & Free & $\begin{array}{l}1507 \\
(196)\end{array}$ & Free & $\begin{array}{l}\mathrm{NH} \\
\text { Gly } \\
\text { bend }\end{array}$ & $\begin{array}{l}1492 \\
(553)\end{array}$ & $C_{5}$ & $\begin{array}{l}\text { Mostly } \\
\text { NH gly } \\
\text { bend (in } \\
\text { phase) }\end{array}$ & $\begin{array}{l}1491 \\
(720)\end{array}$ & & $\begin{array}{l}\text { Mostly } \\
\text { NH Gly } \\
\text { bend (in } \\
\text { phase) }^{\mathrm{a}}\end{array}$ \\
\hline & & $\mathrm{b}$ & & $\begin{array}{l}1511 \\
(335)\end{array}$ & $\pi$ & $\begin{array}{l}1514 \\
(288)\end{array}$ & $\pi$ & $\begin{array}{l}\mathrm{NH} \\
\text { Phe } \\
\text { bend }\end{array}$ & $\begin{array}{l}1518 \\
(74)\end{array}$ & Free & $\begin{array}{l}\text { mostly } \\
\text { NH Phe } \\
\text { bend } \\
\text { (out of }_{\text {phase) }}{ }^{\mathrm{a}}\end{array}$ & $\begin{array}{c}1514 \\
(48)\end{array}$ & $C_{5}$ & $\begin{array}{l}\text { Mostly } \\
\text { NH Phe } \\
\text { bend } \\
\text { (out of }^{\text {phase) }}{ }^{\mathrm{a}}\end{array}$ \\
\hline & 1588 & & 1595 & $\begin{array}{l}1597 \\
(73)\end{array}$ & $C_{10}$ & $\begin{array}{l}1603 \\
(72)\end{array}$ & $C_{10}$ & $\begin{array}{l}\mathrm{NH}_{2} \\
\text { sym } \\
\text { bend }\end{array}$ & $\begin{array}{l}1599 \\
(175)\end{array}$ & $C_{7}$ & $\begin{array}{c}\mathrm{NH}_{2} \\
\text { sym } \\
\text { bend }\end{array}$ & $\begin{array}{l}1601 \\
(70)\end{array}$ & $\pi$ & $\begin{array}{c}\mathrm{NH}_{2} \text { sym } \\
\text { bend }\end{array}$ \\
\hline \multirow{3}{*}{$\begin{array}{l}\text { Amide I } \\
\text { region } \\
\text { (CO } \\
\text { stretch) }\end{array}$} & 1687 & & 1694 & $\begin{array}{l}1702 \\
(336)\end{array}$ & $C_{10}$ & $\begin{array}{l}1692 \\
(431)\end{array}$ & $C_{10}$ & $\begin{array}{c}\mathrm{CO} \\
\text { Ace } \\
\text { stretch }\end{array}$ & $\begin{array}{l}1686 \\
(282)\end{array}$ & $C_{7}$ & $\begin{array}{l}\text { mostly } \\
\text { CO Gly } \\
\text { stretch }\end{array}$ & $\begin{array}{l}1691 \\
(483)\end{array}$ & Free & $\begin{array}{l}\text { CO Gly } \\
\text { stretch }\end{array}$ \\
\hline & 1707 & $\mathrm{~b}$ & 1721 & $\begin{array}{l}1718 \\
(287)\end{array}$ & Free & $\begin{array}{l}1718 \\
(295)\end{array}$ & Free & $\begin{array}{l}\text { CO } \\
\text { Phe } \\
\text { stretch }\end{array}$ & $\begin{array}{l}1710 \\
(174)\end{array}$ & Free & $\begin{array}{l}\text { CO Ace } \\
\text { stretch }\end{array}$ & $\begin{array}{l}1709 \\
(79)\end{array}$ & $C_{5}$ & $\begin{array}{l}\text { CO Ace } \\
\text { stretch }\end{array}$ \\
\hline & $1719^{c}$ & & & $\begin{array}{l}1724 \\
(382)\end{array}$ & Free & $\begin{array}{l}1725 \\
(299)\end{array}$ & Free & $\begin{array}{c}\text { Gly } \\
\text { stretch }\end{array}$ & $\begin{array}{l}1738 \\
(417)\end{array}$ & Free & $\begin{array}{l}\text { CO Phe } \\
\text { stretch }\end{array}$ & $\begin{array}{l}1728 \\
(349)\end{array}$ & $C_{5}$ & $\begin{array}{l}\text { CO Phe } \\
\text { stretch }\end{array}$ \\
\hline \multirow{4}{*}{$\begin{array}{l}\text { Amide } A \\
\text { region } \\
\text { (NH } \\
\text { stretch) }\end{array}$} & 3388 & 3389 & 3385 & $\begin{array}{l}3391 \\
(184)\end{array}$ & $C_{10}$ & $\begin{array}{l}3380 \\
(268)\end{array}$ & $C_{10}$ & $\begin{array}{l}\mathrm{NH}_{2} \\
\text { sym } \\
\text { stretch }\end{array}$ & $\begin{array}{l}3371 \\
(106)\end{array}$ & $C_{7}$ & $\begin{array}{c}\mathrm{NH}_{2} \\
\text { sym } \\
\text { stretch }\end{array}$ & $\begin{array}{l}3405 \\
(103)\end{array}$ & $C_{5}$ & $\begin{array}{l}\text { NH Phe } \\
\text { stretch }\end{array}$ \\
\hline & 3442 & 3443 & 3443 & $\begin{array}{c}3454 \\
(37)\end{array}$ & $\pi$ & $\begin{array}{c}3453 \\
(41)\end{array}$ & $\pi$ & $\begin{array}{l}\mathrm{NH} \\
\text { Phe } \\
\text { stretch }\end{array}$ & $3450(57)$ & $C_{5}$ & $\begin{array}{l}\text { mostly } \\
\text { NH gly } \\
\text { stretch }\end{array}$ & $\begin{array}{l}3427 \\
(45)\end{array}$ & $\pi$ & $\begin{array}{c}\mathrm{NH}_{2} \text { sym } \\
\text { stretch }\end{array}$ \\
\hline & d & d & d & $\begin{array}{c}3480 \\
(26)\end{array}$ & Free & $\begin{array}{c}3487 \\
(38)\end{array}$ & Free & $\begin{array}{l}\mathrm{NH} \\
\text { Gly } \\
\text { stretch }\end{array}$ & $3452(59)$ & Free & $\begin{array}{l}\text { mostly } \\
\text { NH Phe } \\
\text { stretch }\end{array}$ & $\begin{array}{l}3443 \\
(102)\end{array}$ & $C_{5}$ & $\begin{array}{l}\text { NH Gly } \\
\text { stretch }\end{array}$ \\
\hline & 3519 & 3523 & 3521 & $\begin{array}{l}3525 \\
(104)\end{array}$ & Free & $\begin{array}{l}3519 \\
(106)\end{array}$ & Free & $\begin{array}{c}\mathrm{NH}_{2} \\
\text { anti } \\
\text { stretch }\end{array}$ & 3517 (84) & Free & $\begin{array}{l}\mathrm{NH}_{2} \text { anti } \\
\text { stretch }\end{array}$ & $\begin{array}{c}3546 \\
(63)\end{array}$ & Free & $\begin{array}{c}\mathrm{NH}_{2} \text { anti } \\
\text { stretch }\end{array}$ \\
\hline
\end{tabular}

${ }^{a}$ The NH bending modes of Phe and Gly are strongly coupled to each other as well as to $\mathrm{C}-\mathrm{N}$ backbone stretches.

${ }^{\mathrm{b}}$ The 5-8 $\mu \mathrm{m}$ spectrum of conformer $B$ of Ac-Ala-Phe- $\mathrm{NH}_{2}$ could not been measured.

${ }^{\mathrm{c}}$ Shoulder of the $1707 \mathrm{~cm}^{-1}$ band.

${ }^{\mathrm{d}}$ The missing NH stretching band is located in the absorption region of the OPO crystal.

can be found. For example, the double $\gamma$-folded structure exhibits four basic geometries depending upon the chirality $\left(\gamma_{\mathrm{L}}\right.$ or $\left.\gamma_{\mathrm{D}}\right)$ of each $\gamma$-fold. ${ }^{2,6,45} \beta$-turns exist under four major types labeled I, II, I' and $\mathrm{II}^{\prime}$, all exhibiting a $C_{10}$ H-bond. ${ }^{16}$ Types I and II mainly differ by a $180^{\circ}$ flip of the central amide unit, types I' and II' are mirror images of the unprimed species; the chirality of the residues being unchanged. Type $\mathrm{I}$ is the most common turn in proteins and type II' has been found nearly exclusively specific of Gly in the first position of the central part of the turn. ${ }^{46,47}$ In addition, the side-chain Phe can exist in three orientations, labeled anti, gauche + and gauche - $(a, g+$ and $g-)$ according to the value of the dihedral angle $\mathrm{N}-\mathrm{C}_{\alpha}-\mathrm{C}_{\beta}-\mathrm{C}_{\gamma}$ describing the Phe orientation. ${ }^{35,41}$ All these differences do not change drastically the backbone topology and similar IR spectra are expected for all conformations along the same family. An exception may be the NH-aromatic interaction, which may be favored by some Phe side-chain orientations. The energy differences between these similar forms are often below the precision expected for the calculation (typically 1 $\mathrm{kcal} / \mathrm{mol}$ ) ${ }^{35,41}$ For this reason, the experimental data (Figs. 2 and 3) have been compared to the calculated spectra of selected members of the four major types of conformations. Were selected those able to account not only for the H-bonds but also for the presence or absence of $\mathrm{NH}-\pi$ interactions, namely, in the Ramachandran terminology, $\gamma_{\mathrm{L}}-\gamma_{\mathrm{L}}(g-)$ and 
$\gamma_{\mathrm{D}^{-}} \gamma_{\mathrm{D}}(g-)$ for $C_{7}-C_{7}, \beta_{\mathrm{L}^{-}} \beta_{\mathrm{L}}(a)$ for $C_{5^{-}} C_{5}$, types I $(g+)$ and $\mathrm{II}^{\prime}(g+)$ for the $\beta$-turns $\left(C_{10}\right)$ and $\beta_{\mathrm{L}}-\gamma_{\mathrm{L}}(g-)$ for $C_{5}-C_{7}$.

For conformers $A$ [Figs. 2(a) and 2(b); Table I], the redshifted bands in the amide $A$ and I regions match well the calculated $C_{7}$ features of the double $\gamma$-folded family. In the latter region, the band that is shifted to the red displays a doublet which is only partially resolved for $X x x=$ Gly and Ala. The amide II region is also well reproduced by the $\gamma_{\mathrm{L}}-\gamma_{\mathrm{L}}$ backbone, which suggests to assign this structure to conformers $A$. In the amide $A$ region, one can remark that the missing fourth band in the experimental spectrum is found to be located in the spectral region not covered by the crystal OPO.

For conformers $B$ [Figs. 3(a) and 3(b); Table II], neither the $C_{5}-C_{5}$ nor the $C_{5}-C_{7}$ conformation fits well the unique, slightly red-shifted, amide $A$ bands and the barely resolved features in the amide I region. The calculated $C_{5}-C_{7}$ conformation exhibits a too strong $C_{7}$ signature compared to experiment, as indicated by mismatches for both the red most band in amide $A$ region and the splitting of the amide I triplet. For the $C_{5}-C_{5}$ conformation, in the amide $A$ region, the calculated free $\mathrm{NH}_{2}$ antisymmetric stretch cannot account for the blue most band, nor can the $C_{5}$ interaction fit the red most NH band, despite the significant red-shift calculated for such a $C_{5}$ interaction, ${ }^{35}$ which is probably indicative of cooperative effects within the $\beta$-strand structure. Similarly, the calculated triplet showing well-spaced $\mathrm{CO}$ modes is not found in the experiment. In contrast, the weak $C_{10} \mathrm{H}$-bond of either of the two $\beta$-turns reproduces quite satisfactorily the experimental IR data of conformers $B$. This confirms the initial $\beta$-turn assignment to conformers $B$. The band in the $3440 \mathrm{~cm}^{-1}$ region, also reproduced by calculations, does correspond to the $\mathrm{NH}_{\text {Phe }}$ group involved in a weak interaction with the aromatic ring in a $(g+)$ orientation. Such an interaction is not present in conformers $A$. However, neither this $\mathrm{NH}-\pi$ interaction (not specific of the $\beta$-turn type ${ }^{45}$ ), nor the IR spectroscopy (not sensitive enough to distinguish subtle differences in backbone arrangements) permits to assign the type of turn. In particular, one should mention that the type might differ along the series of peptides considered. Protein x-ray data indeed suggest that, in contrast to types II and II' which should be regarded as specific to the presence of Gly, type I $\beta$-turns can be formed from a large diversity of residues. ${ }^{46,47}$

Finally, one should mention that the present assignments are consistent with the relative energies obtained at a high level of theory $[\mathrm{MP} 2 / 6-31+\mathrm{G}(d) / / \mathrm{B} 3 \mathrm{LYP} / 6-31+\mathrm{G}(d)]$. $^{45}$ In Ac-Gly-Phe- $\mathrm{NH}_{2}$, both $\beta$-turns considered here are found to be of similar stability, followed by the $\gamma_{\mathrm{L}}-\gamma_{\mathrm{L}}(g-)$ and $\gamma_{\mathrm{D}^{-}} \gamma_{\mathrm{D}}(g-)$ conformations with +0.6 and $+1.2 \mathrm{kcal} / \mathrm{mol}$, respectively. The $\beta$-strand $\left[\beta_{\mathrm{L}}-\beta_{\mathrm{L}}(a)\right]$ and its variant $\beta_{\mathrm{L}}-\gamma_{\mathrm{L}}(g-)$ structure are much higher in energy by +3.8 and $+5.0 \mathrm{kcal} / \mathrm{mol}$, respectively. The close topology of the $\beta_{\mathrm{L}}-\gamma\left(C_{5}-C_{7}\right)$ and $\beta_{\mathrm{L}}-\beta_{\mathrm{L}}\left(C_{5}-C_{5}\right)$ forms as well as their relative energy compared to the $\gamma-\gamma\left(C_{7}-C_{7}\right)$ conformation explain that the first two forms can convert into the latter during the expansion. In contrast, the structural specificities of the $\beta$-turns together with their high stability ensure their significant abundance at high temperature as well as the preservation of the $C_{10}$ bond during the expansion.

The changes of the $\beta$-turn abundance along the series of the model peptides studied, in particular the remarkably large $\beta$-turn population in Ac-Val-Phe- $\mathrm{NH}_{2}$, also suggest to examine the role of side-chains on the relative stabilities of $\gamma-\gamma$ and $\beta$-turn forms. Examination of both types of structures [Figs. 2(c) and 3(c)] shows that close contacts between Phe and Val side chains are only possible in $\beta$-turns, provided an appropriate chain orientation. In such a case, dispersive interaction can significantly increase the stability of $\beta$-turns. In the other cases studied, the short side chain of the Gly and Ala residues do not permit such a close contact with the phenyl ring. These considerations qualitatively account for the population changes observed along the series studied, in particular the prevalence of $\beta$-turn with Ac-Val-Phe- $\mathrm{NH}_{2}$.

\section{CONCLUDING REMARKS}

The well-resolved IR signatures observed for several conformers formed in a supersonic expansion in comparison to DFT calculations enable us to derive the type of interactions present in the peptide chains as well as to distinguish between several types of backbone folding. The present experiment establishes the intrinsic stability of $\beta$-turns in short gas phase peptides, showing that a relatively weak $C_{10}$ bond is sufficient to stabilize this conformation, without the help of the environment (solvent or neighboring residues) like in a $\beta$-hairpin. In all cases, $\beta$-turn is competing with another secondary structure, the double $\gamma$-fold, corresponding to the $2_{7}$ ribbon. The topologically close $\beta$-strand secondary structure is not observed.

The present results also emphasize the robustness of the $\beta$-turn structure with respect to the nature of the residues in the sequence: $\beta$-turns are observed in all the three systems studied, with a remarkable abundance in Ac-Val-Phe- $\mathrm{NH}_{2}$. Due to the fast cooling rates in the supersonic jet, the final conformational populations are likely to reflect the relative stabilities of the different classes of structures at the very beginning of the expansion, i.e., under temperature conditions close to ambient, rather than at low temperature. In this respect jet experiments appear as an efficient tool to qualitatively assess the relative stabilities of $\beta$-turns by comparing them to other competing forms. These results also show that the relative stabilities of the competing conformations $(\beta$ turns and $\gamma-\gamma$ ) are widely influenced by the weak interactions between bulky side chains. This suggests that, in proteins, the $\beta$-turn formation might also be very sensitive to the interactions experienced by the side chains.

\section{ACKNOWLEDGMENTS}

The authors gratefully acknowledge the support by the Stichting voor Fundamenteel Onderzoek der Materie (FOM) in providing the required beam time on FELIX and highly appreciate the skillful assistance by the FELIX staff. This work was supported by the European Community-Research Infrastructure Action under the FP6 "Structuring the Euro- 
pean Research Area" Program through the Integrated Infrastructure Initiative "Integrating Activity on Synchrotron and Free Electron Laser Science."

${ }^{1}$ A. Perczel and I. G. Csizmadia, Int. Rev. Phys. Chem. 14, 127 (1995), and references therein.

${ }^{2}$ M. D. Beachy, D. Chasman, R. B. Murphy, T. A. Halgren, and R. A. Friesner, J. Am. Chem. Soc. 119, 5908 (1997), and references therein.

${ }^{3}$ K. Möhle, M. Gussmann, and H. J. Hofmann, J. Comput. Chem. 18, 1415 (1997), and references therein.

${ }^{4}$ R. Improta, V. Barone, K. N. Kudin, and G. E. Scuseria, J. Am. Chem. Soc. 123, 3311 (2001).

${ }^{5}$ Y. D. Wu and Y. L. Zhao, J. Am. Chem. Soc. 123, 5313 (2001).

${ }^{6}$ M. Elstner, K. J. Jalkanen, M. Knapp-Mohammady, T. Frauenheim, and S. Suhai, Chem. Phys. 263, 203 (2001).

${ }^{7}$ I. A. Topol, S. K. Burt, E. Deretey, T. H. Tang, A. Perczel, A. Rashin, and I. G. Csizmadia, J. Am. Chem. Soc. 123, 6054 (2001).

${ }^{8}$ R. Vargas, J. Garza, B. P. Hay, and D. A. Dixon, J. Phys. Chem. A 106, 3213 (2002).

${ }^{9}$ M. Elstner, K. J. Jalkanen, M. Knapp-Mohammady, T. Frauenheim, and S. Suhai, Chem. Phys. 256, 15 (2000).

${ }^{10}$ P. Chaudhuri and S. Canuto, J. Mol. Struct.: THEOCHEM 577, 267 (2002).

${ }^{11}$ P. Bour, J. Kubelka, and T. A. Keiderling, Biopolymers 65, 45 (2002), and references therein.

${ }^{12}$ A. Perczel, I. Jakli, M. A. McAllister, and I. G. Csizmadia, Chem.-Eur. J. 9, 2551 (2003).

${ }^{13}$ A. Perczel, I. Jakli, and I. G. Csizmadia, Chem.-Eur. J. 9, 5332 (2003).

${ }^{14}$ R. Wieczorek and J. J. Dannenberg, J. Am. Chem. Soc. 125, 14065 (2003), and references therein.

${ }^{15}$ R. Wieczorek and J. J. Dannenberg, J. Am. Chem. Soc. 125, 8124 (2003), and references therein.

${ }^{16}$ C. Toniolo, CRC Crit. Rev. Biochem. 9, 1 (1980), and references therein.

${ }^{17}$ J. A. Smith and L. G. Pease, CRC Crit. Rev. Biochem. 8, 314 (1980), and references therein.

${ }^{18}$ G. D. Rose, L. M. Gierasch, and J. A. Smith, Adv. Protein Chem. 37, 1 (1985), and references therein.

${ }^{19}$ E. Vass, M. Hollosi, F. Besson, and R. Buchet, Chem. Rev. (Washington, D.C.) 103, 1917 (2003), and references therein.

${ }^{20}$ J. R. Cable, M. J. Tubergen, and D. H. Levy, J. Am. Chem. Soc. 111, 9032 (1989).

${ }^{21}$ F. Piuzzi, I. Dimicoli, M. Mons, B. Tardivel, and Q. Zhao, Chem. Phys. Lett. 320, 282 (2000).

${ }^{22}$ E. G. Robertson and J. P. Simons, Phys. Chem. Chem. Phys. 3, 1 (2001), and references therein.
${ }^{23}$ T. S. Zwier, J. Phys. Chem. A 105, 8827 (2001), and references therein.

${ }^{24}$ R. Cohen, B. Brauer, E. Nir, L. Grace, and M. S. de Vries, J. Phys. Chem. A 104, 6351 (2000).

${ }^{25}$ L. C. Snoek, E. G. Robertson, R. T. Kroemer, and J. P. Simons, Chem. Phys. Lett. 321, 49 (2000).

${ }^{26}$ L. C. Snoek, R. T. Kroemer, M. R. Hockridge, and J. P. Simons, Phys. Chem. Chem. Phys. 3, 1819 (2001).

${ }^{27}$ K. T. Lee, J. Sung, K. J. Lee, Y. D. Park, and S. K. Kim, Angew. Chem., Int. Ed. 41, 4114 (2002).

${ }^{28}$ J. M. Bakker, L. M. Aleese, G. Meijer, and G. von Helden, Phys. Rev. Lett. 91, 203003 (2003).

${ }^{29}$ I. Hünig, K. A. Seefeld, and K. Kleinermanns, Chem. Phys. Lett. 369, 173 (2003)

${ }^{30}$ I. Hünig and K. Kleinermanns, Phys. Chem. Chem. Phys. 6, 2650 (2004).

${ }^{31}$ B. C. Dian, A. Longarte, S. Mercier, D. A. Evans, D. J. Wales, and T. S. Zwier, J. Chem. Phys. 117, 10688 (2002).

${ }^{32}$ B. C. Dian, A. Longarte, and T. S. Zwier, Science 296, 2369 (2002), and references therein.

${ }^{33}$ R. Weinkauf, J. P. Schermann, M. S. de Vries, and K. Kleinermanns, Eur. Phys. J. D 20, 309 (2002).

${ }^{34}$ C. Unterberg, A. Gerlach, T. Schrader, and M. Gerhards, J. Chem. Phys. 118, 8296 (2003), and references therein.

${ }^{35}$ W. Chin, M. Mons, J.-P. Dognon, F. Piuzzi, B. Tardivel, and I. Dimicoli, Phys. Chem. Chem. Phys. 6, 2700 (2004).

${ }^{36}$ M. Gerhards, C. Unterberg, A. Gerlach, and A. Jansen, Phys. Chem. Chem. Phys. 6, 2682 (2004).

${ }^{37}$ R. J. Lavrich, D. F. Plusquellic, R. D. Suenram, G. T. Fraser, A. R. H. Walker, and M. J. Tubergen, J. Chem. Phys. 118, 1253 (2003).

${ }^{38}$ K. Möhle, M. Gussmann, A. Rost, R. Cimiraglia, and H. J. Hofmann, J. Phys. Chem. A 101, 8571 (1997).

${ }^{39}$ G. Endredi, A. Perczel, O. Farkas, M. A. McAllister, G. I. Csonka, J. Ladik, and I. G. Csizmadia, J. Mol. Struct.: THEOCHEM 391, 15 (1997).

${ }^{40}$ P. Hudaky, I. Jakli, A. G. Csaszar, and A. Perczel, J. Comput. Chem. 22, 732 (2001), and references therein.

${ }^{41}$ W. Chin, M. Mons, J.-P. Dognon et al., J. Phys. Chem. A (to be published).

${ }^{42}$ M. J. Frisch, G. W. Trucks, H. B. Schlegel et al., GAUSSIAN 98, Gaussian, Inc., Pittsburg, PA, 1998.

${ }^{43}$ T. Nakanaga and F. Ito, J. Phys. Chem. A 103, 5440 (1999).

${ }^{44}$ E. G. Robertson, M. R. Hockridge, P. D. Jelfs, and J. P. Simons, Phys. Chem. Chem. Phys. 3, 786 (2001).

${ }^{45}$ W. Chin, J.-P. Dognon, F. Piuzzi, B. Tardivel, I. Dimicoli, and M. Mons, J. Am. Chem. Soc. (in press).

${ }^{46}$ K. Guruprasad and S. Rajkumar, J. Biosci. Bioeng. 25, 143 (2000).

${ }^{47}$ E. G. Hutchinson and J. M. Thornton, Protein Sci. 3, 2209 (1994). 